\title{
Targeting the Epithelial-to-Mesenchymal Transition: The Case for Differentiation-Based Therapy
}

\author{
Diwakar R. Pattabiraman ${ }^{1}$ and Robert A. Weinberg ${ }^{1,2,3}$ \\ ${ }^{1}$ Whitehead Institute for Biomedical Research, Cambridge, Massachusetts 02142 \\ ${ }^{2}$ Department of Biology, Massachusetts Institute of Technology, Cambridge, Massachusetts 02142 \\ ${ }^{3}$ Ludwig/MIT Center for Molecular Oncology, Cambridge, Massachusetts 02139
}

Correspondence: weinberg@wi.mit.edu

\begin{abstract}
Although important strides have been made in targeted therapy for certain leukemias and subtypes of breast cancer, the standard of care for most carcinomas still involves chemotherapy, radiotherapy, surgery, or a combination of these. Two processes serve as obstacles to the successful treatment of carcinomas. First, a majority of deaths from these types of cancers occurs as a result of distant metastases and not the primary tumors themselves. Second, subsets of cells that are able to survive conventional therapy drive the aggressive relapse of the tumors, often in forms that are resistant to treatment. A frequently observed feature of malignant carcinomas is the loss of epithelial traits and the gain of certain mesenchymal ones that are programmed by the cell-biological program termed the epithelial-to-mesenchymal transition (EMT). The EMT program can confer (i) an ability to disseminate, (ii) an ability to become stem-like tumor-initiating cells, (iii) an ability to found new tumor colonies at distant anatomical sites, and (iv) an elevated resistance to therapy. These multiple powers of the EMT program explain why it has become an attractive target for therapeutic intervention. Recent work has revealed the variable nature of the EMT, with multiple versions of the program being observed depending on the tissue context and the stage of tumor progression. In this review, we attempt to crystallize emerging concepts in the research on EMT and stemness and discuss the benefits of using a differentiation-based therapeutic strategy for the eradication of stem-like populations that have adopted various versions of the EMT program.
\end{abstract}

The epithelial-to-mesenchymal transition (EMT) is a cell-biological program that is important in various aspects of development, wound healing, maintenance of stemness, and tumor progression. Initial observations of the loss of epithelial properties and the concomitant gain of mesenchymal traits were made in the laboratory of Elizabeth Hay, who studied the development of cornea, limb, notochord, and lens epithelia (Greenburg and Hay 1982). These findings have opened an entire field of research, which associates EMT programs with a multitude of distinct pathophysiologic processes, including the malignant progression and metastatic dissemination of carcinomas. The transition involves a highly coordinated program whereby epithelial cells loose their characteristics of apical-basal polarity, cell-cell junctions and adherence to the basement membrane and gain, among other traits, certain properties of mesenchymal cells that enable them to migrate and invade. The EMT is known to occur in various different biological contexts, which has led to its classification into three different types (Kalluri and Weinberg 2009). A type I EMT refers to the transition that takes place in the context of development, including processes that give rise to the mesoderm and primary mesenchyme from the primitive streak during gastrulation, as well as those that give rise to the migratory neural crest cells. The type II EMT is utilized during process of tissue regeneration, such as transient fibrosis and wound healing. The version of EMT highlighted in the present discussion is the type III EMT, which is associated with tumor progression.

\section{EMT IN TUMOR PROGRESSION}

Over the past decade, the importance of the EMT program in tumor progression has been established by hundreds of studies in a wide variety of carcinomas, including breast, ovarian, pancreatic, prostate, colorectal, and renal types. The role of the EMT in tumor progression has been comprehensively reviewed elsewhere (De Craene and Berx 2013; Tsai and Yang 2013; Nieto et al. 2016) and is not the major focus of the present review. Briefly, the acquisition of mesenchymal traits through induction of an EMT program is thought to enable carcinoma cells to complete many of the steps of the invasion-metastasis cascade - the sequence of steps that begins with the local invasiveness of the neoplastic cells within primary tumors, their intravasation, translocation through the circulation, extravasation into the parenchyma of distant tissues, the founding of micrometastatic deposits, and the

(C) 2016 Pattabiraman and Weinberg. This article is distributed under the terms of the Creative Commons Attribution-NonCommercial License, which permits reuse and redistribution, except for commercial purposes, provided that the original author and source are credited. 
outgrowth of these deposits into macroscopic metastases - the last step being termed "colonization" (Fidler 2003; Yang et al. 2004). Expression of the EMT is maintained during the early and intermediate stages of the cascade, including invasion through tissue around the primary tumor, intravasation, transportation as circulating tumor cells (CTCs) in the vasculature (Yu et al. 2013), and extravasation following their vascular journey (Labelle et al. 2011). Following extravasation, disseminated tumor cells may undergo the reverse of the EMT, termed the mesenchymal-to-epithelial transition (MET) and thereby regain the epithelial traits exhibited by their progenitors within the primary tumor (MET) (Ocana et al. 2012; Tsai et al. 2012); this last step appears to be critical to allow metastatic colonization to proceed efficiently.

\section{ALTERNATIVE VERSIONS OF TUMOR CELL DISSEMINATION}

Several reports now show that the escape of carcinoma cells from primary tumors, as enabled by an EMT program, can occur by other mechanisms besides the frequently studied single-cell dissemination. In particular, the process of collective invasion has been widely reported and occurs when cohorts of cells that held together by cell-cell junctions advance through the extracellular matrix (Friedl and Gilmour 2009; Friedl et al. 2012). In fact, three-dimensional reconstruction studies of tumors have shown that single cell dissemination is, by contrast, relatively rare, with cell clusters being the prevalent agents of invasion (Bronsert et al. 2014). The polyclonal nature of certain metastatic colonies is consistent with their having arisen through collective dissemination of tumor cell clusters (Cheung et al. 2016), rather than from disseminated single cells, which would ostensibly give rise to monoclonal metastatic colonies. The expression of E-cadherin - a key marker of the epithelial cell statethroughout the bulk of these invasive masses has led some to question the involvement of EMT in the process of carcinoma invasiveness. However, certain lines of evidence indicate that the cells at the leading edges of invasive cohorts express certain EMT characteristics (Revenu and Gilmour 2009; Westcott et al. 2015; Ye et al. 2015). At present, it has not yet been demonstrated directly that the EMT characteristics expressed by these leader cells, including notably the trait of invasiveness, are critical to the forward migration of the cohorts as a whole.

Additionally, two recent studies using lineage-tracing studies in mouse models of breast and pancreatic cancer have questioned the essential role of the EMT program in the process of metastasis (Fischer et al. 2015; Zheng et al. 2015). Fischer et al. used Fsp1 as a lineage-tracing marker of cells that have undergone an EMT and found that large numbers of Fsp1-negative cells formed metastases in the lung. These results were interpreted as EMT not having been expressed, even transiently, for the formation of metastases. Although Fsp1 is expressed in certain versions of the EMT program (e.g., in renal tubular cells [Okada et al. 1997]), it cannot be used as a reliable marker of activation of an EMT program, especially in the absence of convincing data proving that Fsp1 is actually expressed in a majority of cells undergoing an EMT. A second paper utilized a lineage-traced mouse model of pancreatic ductal adenocarcinoma (PDAC), which exhibited a significant reduction in the percentage of $\alpha$-smooth muscle actin ( $\alpha$ SMA)-expressing cells relative to tumors with an intact Twist locus (Zheng et al. 2015). As described above, use of $\alpha$ SMA expression as a reliable marker of EMT is complicated by the fact that it is rarely induced spontaneously upon activation of EMT during the course of tumor development (Aiello NM and Stanger $\mathrm{BZ}$, unpubl.) in this particular mouse tumor model, undermining the conclusions presented in this report. To summarize, we believe that neither of these papers proved that the EMT did not occur in the metastasizing carcinoma cells, leaving intact the notion that the EMT is indeed necessary for the metastatic dissemination of carcinoma cells. However, these two reports highlight the fact that the EMT is not a single, stereotypical program, and that various versions of this program are expressed under different conditions in a variety of carcinomas. This portrayal of multiple versions of the EMT program will be discussed further below.

\section{EMT AND STEMNESS}

Since the initial discovery of the connection between breast carcinomas that have undergone an EMT and the entrance into a stem-like state (Mani et al. 2008; Morel et al. 2008), a number of studies have extended these findings to report similarly the acquisition of stemness following the EMT in multiple tumor types, including colorectal (Fan et al. 2012), ovarian (Long et al. 2015), pancreatic (Rasheed et al. 2010), prostate (Kong et al. 2010), and renal (Zhou et al. 2016), among other types of carcinomas. Additionally, the EMT program has also been shown to be important for the normal mammary epithelial stem cell state (Guo et al. 2012; Nassour et al. 2012).

Although the connection between the EMT and acquisition of stem-like properties is now widely accepted, not all cells that have undergone an EMT exhibit increased stemness. Thus, several studies have reported the loss of stem-like properties in carcinomas upon undergoing an EMT (Celia-Terrassa et al. 2012; Chang et al. 2013; Xie et al. 2014), indicating that the acquisition of mesenchymal traits is not, on its own, conducive to acquisition of increased stemness. In more detail, there is increasing evidence that, rather than operating as a binary switch, the EMT program generates cells residing in a spectrum of multiple phenotypic states lying between the fully epithelial and fully mesenchymal states (Fig. 1), and that cells that have passed through a complete EMT program and become entirely mesenchymal actually lack the ability to function as stem cells, both normal and neoplastic. Instead, there is growing evidence that a cell that has only undergone a partial EMT, thereby expressing both 
A

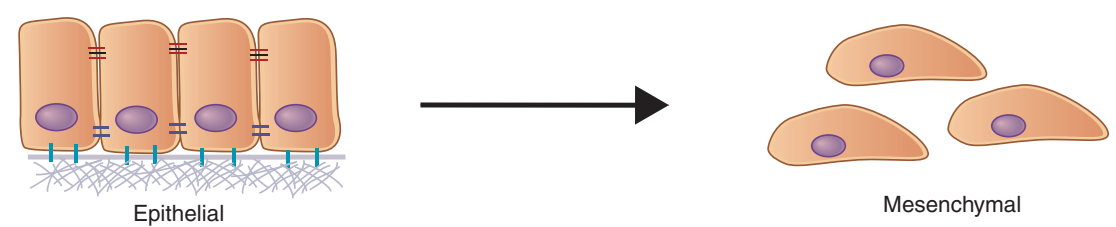

B

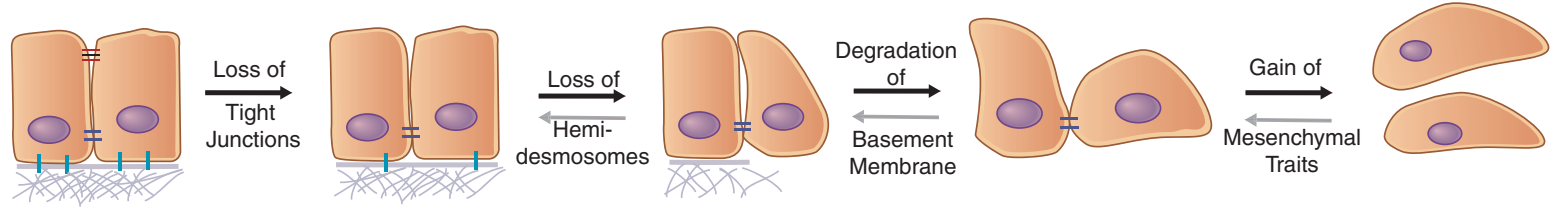

C
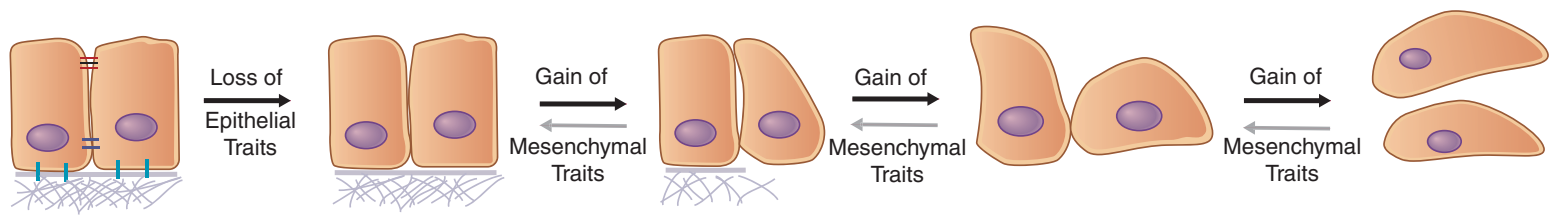

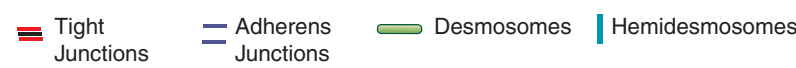

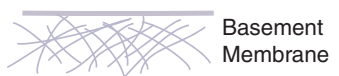

Figure 1. Although we have, in the past, thought of the epithelial-to-mesenchymal transition (EMT) program as a binary switch between two distinct cell states $(A)$, more recent evidence points to the EMT representing a spectrum of different cell states anywhere in between the extreme epithelial and mesenchymal states depending on the state that the cell was originally residing in and the nature of the program that manifests. The sequence of events that defines the EMT is still poorly understood - that is, whether $(B)$ the loss of epithelial traits occurs over multiple steps, with the gain of mesenchymal traits being the final step in the cascade, or if $(C)$ the loss of epithelial traits occurs over a relatively short period of time, followed by a stepwise acquisition of mesenchymal properties.

retained epithelial and acquired mesenchymal traits, is best positioned to acquire stem-like properties (GrosseWilde et al. 2015; Jolly et al. 2015a,b; Andriani et al. 2016).

\section{COULD THE EMT ENCOMPASS THE INITIAL LOSS OF EPITHELIAL TRAITS OBSERVED DURING MALIGNANCY?}

In fact, the actions of the EMT program are not limited to advanced stages of carcinoma progression. Instead, an EMT can also participate in the disruption of the epithelial state that is a common feature of early stages of malignant transformation (Fig. 2). These early steps are characterized by the loss of polarized organization of epithelial tissue (Lee and Vasioukhin 2008), a loss of cell-cell junctions that compromises the barrier function of epithelial tissue (Martin and Jiang 2009), and the degradation of interactions of epithelial cells with the underlying basement membrane (Barsky et al. 1983).

Loss of cell polarity may be the earliest manifestation of the actions of an EMT program. As an example, the overexpressed HER2 protein, which functions as a driver of a significant proportion of breast cancers, disrupts normal apical-basal epithelial cell polarity by interacting with components of the Par polarity complex, including
Par6 and aPKC. Inhibition of these interactions deprives HER2 of its ability to disrupt the acinar organization and polarity of the mammary epithelium, a key event during the initial stages of carcinogenesis (Aranda et al. 2006). Moreover certain proteins that act as tumor suppressors play important roles in maintaining cell polarity-for example, PTEN maintaining apical-basal polarity during epithelial morphogenesis (Martin-Belmonte et al. 2007) and Par3 curbing tumor progression and metastasis (McCaffrey et al. 2012; Li et al. 2014).

These reports indicate the importance of maintaining epithelial polarity as a means of curbing malignancy but do not address whether EMT programs are activated upon loss of polarity. In fact, studies have shown that both the Snail and Zeb family of EMT-inducing transcription factors (EMT-TFs) are capable of repressing the transcription of key polarity genes. Snail is known to repress the transcription of Crumbs3, which codes for a key polarity factor, while also disrupting the localization of the Crumbs and Par complexes (Whiteman et al. 2008). Similarly, Zeb1 also represses transcription of Crumbs3, while also repressing HUGL2, Lgl2, and PATJ in breast and colon cancer cells (Aigner et al. 2007; Spaderna et al. 2008). Loss of Zeb1 enabled a partial restoration of epithelial polarity, demonstrating that the EMT-TFs could be directly responsible for the loss of this epithelial trait. Thus, the loss of polarity that is characteristic of the 
A

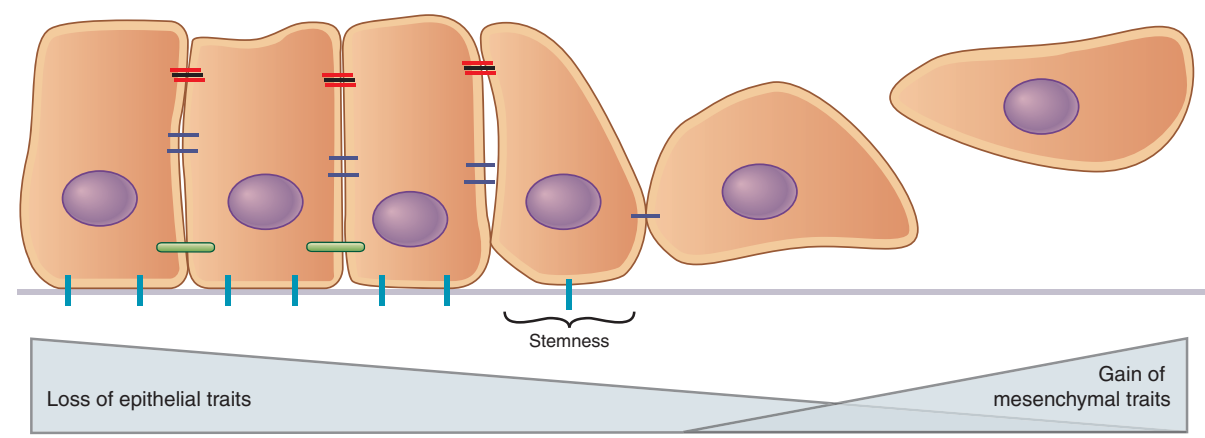

B

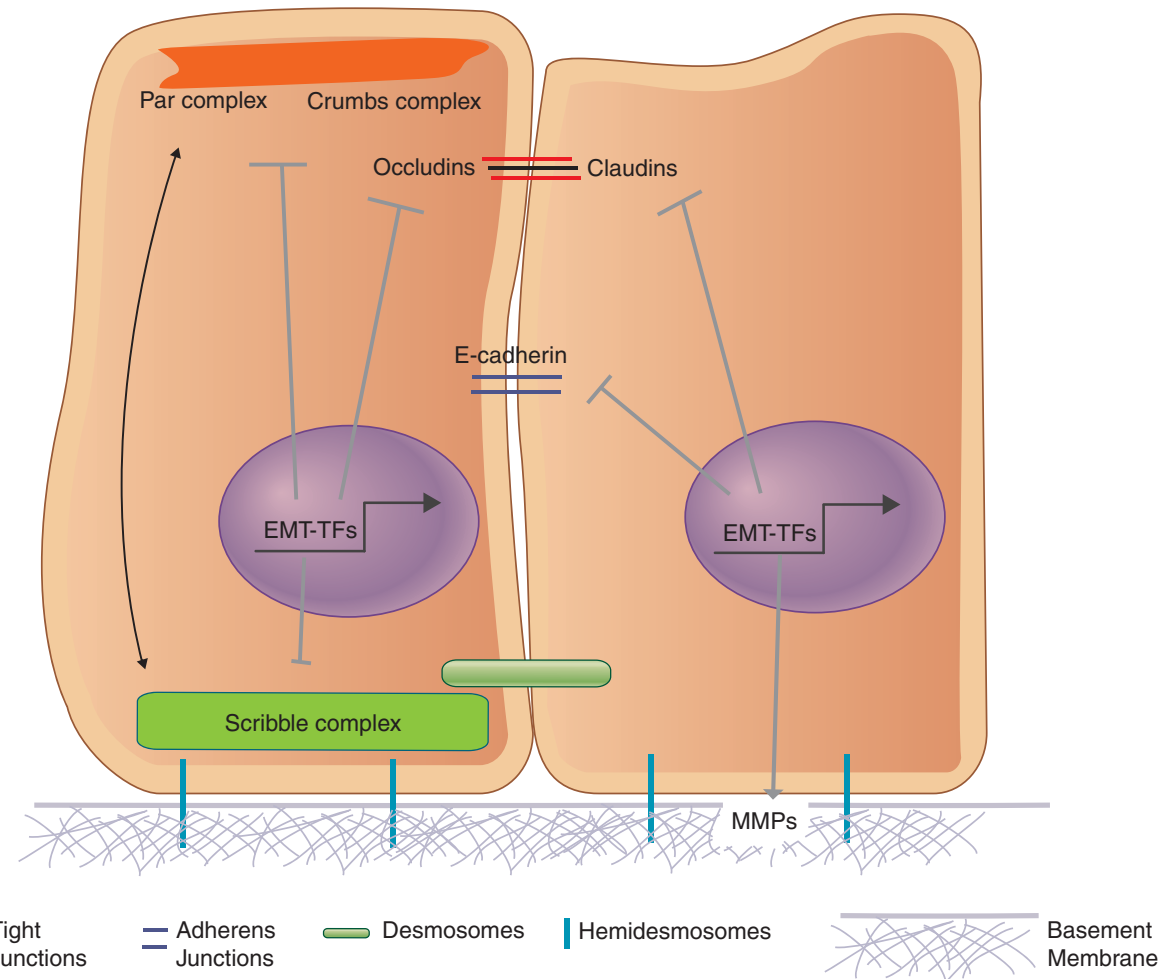

Figure 2. The epithelial-to-mesenchymal transition (EMT) has traditionally been associated, almost exclusively, with the gain of mesenchymal properties. More recent evidence indicates that an overt gain of mesenchymal traits may not be required for the stem-like properties of cells that have undergone an EMT $(A)$. Thus, the ability of the EMT-inducing transcription factors to alter apical-basal polarity and repress the transcription of genes required to maintain cell-cell junctions may be equally important functions of EMTinducing transcription factors $(B)$. Similarly, the role of the EMT-inducing transcriptional factors (EMT-TFs) in inducing the transcription of genes whose products are known to degrade components of the basement membrane is also key in the initial stages of the EMT.

initial stages of carcinogenesis may represent an early manifestation of the EMT program.

Similarly, it has been recognized for some time now that loss of adherens and tight junctions that enable cell-cell adhesions can prevent the acquisition of invasive properties of carcinomas (Frixen et al. 1991; Martin and Jiang 2009). Indeed, multiple studies report the importance of retaining adherens and tight junctions to prevent the acquisition of malignant phenotypes in colorectal (Bornholdt et al. 2011), pancreatic (Takai et al. 2005), and breast carcinomas (Vleminckx et al. 1991; Cavallaro and Christofori 2004; Martin et al. 2010), among others. Thus, together with cell polarity, cell-cell junctions represent key traits associated with cells of epithelial tissue and their architectural organization. These traits are often lost at the initial stages of malignancy, and in many cases, must be lost in order for successful malignant transformation. Here again, it is well documented that the EMT-TFs play a significant role in the disruption of cell junctions through the transcriptional repression of $\mathrm{CDH}$ (Comijn et al. 2001; Hajra et al. 2002; Bolos et al. 2003; Eger et al. 2005), which codes for the key adherens junction protein 
E-cadherin, as well as tight junction proteins such as claudins (Martinez-Estrada et al. 2006) and occludins (Ikenouchi et al. 2003; Ohkubo and Ozawa 2004). Through the repression of these genes, whose products maintain epithelial cell junctions, the EMT program enables an initial advance of carcinoma cell progression toward high-grade malignancy, doing so without the gain of additional overt mesenchymal traits.

Another key property of epithelial tissue is the maintenance of interactions with the basement membrane, which provides structural support while also regulating cell behavior through its ability to control invasion and thereby maintain tissue integrity (Paulsson 1992; Kelley et al. 2014). Snail is known to up-regulate the expression of several matrix metalloproteinase (MMP) genes, including $M M P 9$, which degrades the basement membrane and stimulates tumor cell invasion (Jorda et al. 2005; Miyoshi et al. 2005; Kessenbrock et al. 2010). Additionally, other factors such as Zeb2 and TGF- $\beta$ indirectly activate $M M P 2$ through activation of the Ets-2 transcription factor (Taki et al. 2006). Hence, a variety of EMTinducing signals are capable of repressing key epithelial traits that pave the way for malignancy and tumor progression. Importantly, in none of these cited reports was the full spectrum of EMT-associated mesenchymal traits examined, leaving open the possibility that partial EMT programs, which only involve the loss of certain epithelial traits without gain of a full suite of mesenchymal ones, were launched.

\section{DOES AN EMT INVARIABLY ENTAIL THE ACQUISITION OF OVERT MESENCHYMAL TRAITS?}

As suggested above, increasing evidence indicates that the term EMT subsumes a collection of cell-biological programs rather than a single, stereotypical one. Initially, it was believed that cells that have undergone an EMT resemble fibroblasts (i.e., acquire properties that make them completely mesenchymal). This prompted various efforts to induce as complete an EMT program as experimentally possible, this being undertaken with the preconception that the more complete the EMT, the more aggressive carcinoma cells would appear.

With the passage of time, this thinking has become more nuanced, and we now realize that the acquisition of a full range of EMT-induced mesenchymal traits and associated loss of all epithelial markers is not necessarily correlated with the acquisition by carcinoma cells of aggressive traits and, as discussed above, stemness. Moreover, because different carcinoma cell types exhibit differing proportions of epithelial and mesenchymal traits (Li and Kang 2016), certain studies have attempted to classify breast cancer cells by assigning them scores that would indicate the extent of their EMT-associated features (Tan et al. 2014). Such studies have highlighted a by-now widely embraced notion: there is no standard, stereotypical version of the EMT program. It is therefore likely that in certain cases, aggressive metastasizing car- cinomas may exhibit overt mesenchymal properties that aid its metastatic spread (Trimboli et al. 2008; Bonnomet et al. 2012), whereas in other cases they may not require these properties; moreover, display of these traits may actually be counterproductive for stemness and tumor progression (Celia-Terrassa et al. 2012).

These various reports converge on the increasingly accepted notion that advance partially through an EMT program and resulting residence by carcinoma cells in a partially epithelial, partially mesenchymal state favors tumor progression and metastasis (Lundgren et al. 2009; Jordan et al. 2011; Bednarz-Knoll et al. 2012; Sampson et al. 2014; Grosse-Wilde et al. 2015; Hong et al. 2015; Schliekelman et al. 2015). This suggests, in turn, than an acquisition of overt mesenchymal traits may not be necessary for carcinoma cells to develop aggressive, metastatic properties. Given the prevalence of processes such as collective migration/invasion by tumor cell clusters, as discussed earlier, it is likely that the partial EMT state, which enables some cells to transiently repress certain epithelial properties, is a driving factor for this form of dissemination (Grigore et al. 2016).

\section{REDEFINING THE EMT PROGRAM}

Given the currently rapid progress of EMT research and the extensive literature on this topic that has been produced in recent years, we would propose two guidelines that can be used to understand EMT programs in the context of carcinoma progression and metastasis. First, the EMT appears to generate cells residing in a spectrum of states lying in multiple phenotypic states between the highly organized epithelial state characteristic of normal tissue architecture and the extremely mesenchymal state resembling that of fibroblasts. A transition between any two states within this spectrum to a more mesenchymal state may occur under the aegis of an EMT program (Fig. 1). In the majority of instances, carcinoma cells disseminate by means of tumor cell clusters; the forward march of these clusters does not seem to require an overt transition of the bulk of the cells to a truly mesenchymal state. Instead, the majority of cells in these clusters may have lost certain epithelial traits, such as adherence to a basement membrane and an alteration in their form of cell polarity, whereas subpopulations of cells in these invading cell cohorts, specifically those at the leading/invasive edges of these groups, may indeed express, at least transiently, traits typically associated with EMT programs.

Accordingly, we propose that the EMT program can actually be seen as a program presenting in many different forms: In some forms one may observe the loss of epithelial integrity and architecture while still retaining the expression of certain epithelial markers (Khalil and Friedl 2010; Clark and Vignjevic 2015), whereas in other cases one may observe the adoption of certain mesenchymal traits and markers while still retaining the expression of epithelial traits (McCaffrey et al. 2012; Yu et al. 2013). In yet another version of the EMT program, one may observe a more extended expression of the program that 
involves an almost-complete loss of epithelial traits and a gain of fibroblast-like mesenchymal traits (Bonnomet et al. 2012).

Second, these various versions of the EMT program are united by the fact that members of a small cohort of EMTTFs are expressed in cells that have begun to activate this program, being increasingly expressed as cells advance progressively toward a fully mesenchymal state. These EMT-TFs include prominently Snail, Twist, Slug, and Zeb1, among others (De Craene and Berx 2013). Depending on the nature of the EMT, these factors may be expressed at levels that are sufficient to repress the transcription of certain genes that regulate key epithelial features while not being sufficient to induce the expression of mesenchymal markers. Thus, $C D H 1$, which codes for E-cadherin, can be repressed by a number of EMTTFs, leading to the destabilization of adherens junctions without the concomitant acquisition of overt mesenchymal markers such as vimentin. In other cases, the coexpression of both epithelial and mesenchymal markers is observed in the same cell, indicating the operation of a different transcriptional program that maintains a hybrid state. Nevertheless, it is clear that the version of the EMT program induced is highly dependent on the specific EMT-TF or combination of TFs that are expressed in a particular context.

\section{TARGETING THE EMT THROUGH DIFFERENTIATION-INDUCING THERAPY}

In light of the malignant traits displayed by cancer stem cells (CSCs), an important focus of current research is the identification and targeting of signaling pathways that sustain residence of carcinoma cells in the CSC state. Unfortunately, however, attempts to selectively target carcinoma cells exhibiting exhibit stem-like properties is thwarted by the fact that our understanding of the factors contributing to stemness - including where CSCs lie along the epithelial-mesenchymal spectrum-remains vague at best. Thus, in the absence of knowing which signaling pathways are preferentially activated in the CSCs, the choice of a particular pathway for therapeutic targeting remains arbitrary.

A possibly more attractive therapeutic strategy for dismantling the aggressive traits of CSCs that have acquired EMT-associated traits is a strategy designed to reverse this program by inducing a MET. The induction of an MET in carcinoma cells would ideally involve the forced shedding of mesenchymal traits and a reestablishment of the epithelial cell state, integrity and architecture, which would be accompanied by a loss of stem-like properties.

As mentioned above, it is becoming increasingly clear that as cells undergo an EMT, they slip into a more dedifferentiated state that enhances their ability to resist chemotherapeutic assault (Mani et al. 2008; Morel et al. 2008; Gupta et al. 2009). Hence, the loss of stemness and the process of undergoing differentiation is likely to deprive these cells of traits that fuel their malignant behavior. In fact, the induction of differentiation as a form of therapy was first utilized for the treatment of acute promyelocytic leukemia, where the administration of all-trans retinoic acid was successfully used as a targeted therapy (Warrell et al. 1993). In the case of breast and endometrial carcinomas, the use of histone deacetylase inhibitors (HDACis) induces their differentiation, presumably through the derepression of certain gene promoters (Munster et al. 2001; Uchida et al. 2007; Xu et al. 2007). Along these lines, it appears that processes that serve to maintain the epithelial state of cells act as potent tumor suppressors. This is especially true for features, such as the maintenance of cell polarity (Lee and Vasioukhin 2008), as well as the presence of adherens and tight junctions (Jeanes et al. 2008; Martin and Jiang 2009) between epithelial cells and of hemidesmosomes that maintain interactions with the basement membrane (De Arcangelis et al. 2016). Thus, in the case of carcinomas, it is plausible that processes that maintain the epithelial state are especially relevant for the prevention of malignancy and EMT-induced tumor progression.

As cells undergo an EMT, a series of signaling pathways is activated, while a host of others are down-regulated. The switch in some of these pathways, such as TGF- $\beta$ and Wnt, is initiated by paracrine signals from the tumor-associated stroma, whereas the maintenance of the mesenchymal state is propagated through autocrine signals that maintain their residence in that state (Scheel et al. 2011). Other factors such as PGE2, secreted by mesenchymal stem cells (MSCs), are also known to induce a mesenchymal/CSC state by creating a favorable niche (Li et al. 2012). NF-кB signaling activated by inflammatory cytokines present in the tumor microenvironment also triggers the activation of $\mathrm{NOTCH}$ signaling, which allows expansion of the CSC pool in basal-like breast cancers (Yamamoto et al. 2013). Consequently, it seems that disruption of these paracrine and autocrine signaling axes that maintain residence of tumor cells in a more mesenchymal/stem-like state can force them into a more differentiated epithelial state that would render them more susceptible to conventional therapy. Importantly, such a treatment strategy would restore some of the key traits of epithelial cells, such as the cell-cell junctions that form the foundation of epithelial tissue integrity and morphology.

We recently reported that the elevation of $3^{\prime}, 5^{\prime}$-cyclic adenosine monophosphate (cAMP) levels in certain breast cancer cells can, through the activation of protein kinase A (PKA), induce an MET by enforcing a gene expression program reminiscent of cells that normally exhibit a fully epithelial identity, rendering these cells more susceptible to treatment with conventional chemotherapeutic drugs (Pattabiraman et al. 2016). Activation of such a pathway, which serves to induce and perpetuate residence of cells in an epithelial state, should ideally be an attractive target for differentiation therapy, as it curtails the malignant traits that are associated with tumor progression. Moreover, the continued stimulation of a pathway required for epithelial maintenance is unlikely to have any adverse effects on the already-epithelial, more benign compartment of carcinomas or on the nor- 
mal resident epithelia of the tissue-of-origin. A caveat of using such an MET-induced differentiation therapy in the case of carcinomas is the observed requirement of an MET to complete the colonization stage of the metastasis cascade. Consequently, the induction of an MET might inadvertently support the process of metastatic colonization at distant sites. Nevertheless, the potential of differentiation therapy makes it an attractive strategy for curtailing the malignant and stem-like properties that accompany the induction of an EMT in carcinomas.

\section{CONCLUSION}

Recent findings have provided more insights into the functioning of the EMT program, the nature of its manifestations, and its contribution to tumor progression and resistance to conventional therapy. These developments have furthered our understanding of the spectrum of phenotypic states orchestrated by various versions of the EMT program and provided some evidence for a partial EMT state favoring the CSC state of carcinoma cells. Although the precise mixture of epithelial and mesenchymal traits required for carcinoma cells to enter into a stem-like state is still unknown, there is no longer any doubt that the epithelial state, as characterized by cellcell junctions, apical-basal polarity, and adherence to a basement membrane, is unfavorable for stemness and tumor progression. Hence, forced entrance of carcinoma cells that previously embarked on an EMT program into a more epithelial state likely represents an attractive strategy that can be applied to eradicate the aggressive properties of a wide range of carcinoma cells.

\section{ACKNOWLEDGMENTS}

We thank Dr. Arthur Lambert, Dr. Jordan Krall, Dr. Brian Bierie, and other members of the Weinberg laboratory for helpful discussions and Ms. Meredith Leffler for assistance with the illustrations. D.R.P was supported by a C.J. Martin Overseas Biomedical Fellowship from the National Health and Medical Research Council of Australia (NHMRC APP1071853) and is currently supported by a K99/R00 Pathway to Independence Award (NIH/NCI 1K99CA201574-01A1). The Weinberg laboratory is supported by grants from the National Institutes of Health (NIH; R01 CA078461, P01 CA080111), the Samuel Waxman Cancer Research Foundation, and the Ludwig Center for Molecular Oncology at MIT. R.A.W. is an American Cancer Society Research Professor and a Daniel K. Ludwig Cancer Research Professor.

\section{REFERENCES}

Aigner K, Dampier B, Descovich L, Mikula M, Sultan A, Schreiber M, Mikulits W, Brabletz T, Strand D, Obrist P, et al. 2007. The transcription factor ZEB1 ( $\delta E F 1)$ promotes tumour cell dedifferentiation by repressing master regulators of epithelial polarity. Oncogene 26: 6979-6988.

Andriani F, Bertolini G, Facchinetti F, Baldoli E, Moro M, Casalini P, Caserini R, Milione M, Leone G, Pelosi G, et al. 2016. Conversion to stem-cell state in response to microenvi- ronmental cues is regulated by balance between epithelial and mesenchymal features in lung cancer cells. Mol Oncol 10: 253-271.

Aranda V, Haire T, Nolan ME, Calarco JP, Rosenberg AZ, Fawcett JP, Pawson T, Muthuswamy SK. 2006. Par6-aPKC uncouples ErbB2 induced disruption of polarized epithelial organization from proliferation control. Nat Cell Biol 8: $1235-1245$.

Barsky SH, Siegal GP, Jannotta F, Liotta LA. 1983. Loss of basement membrane components by invasive tumors but not by their benign counterparts. Lab Invest 49: 140-147.

Bednarz-Knoll N, Alix-Panabieres C, Pantel K. 2012. Plasticity of disseminating cancer cells in patients with epithelial malignancies. Cancer Metastasis Rev 31: 673-687.

Bolos V, Peinado H, Perez-Moreno MA, Fraga MF, Esteller M, Cano A. 2003. The transcription factor Slug represses Ecadherin expression and induces epithelial to mesenchymal transitions: A comparison with Snail and E47 repressors. $J$ Cell Sci 116: 499-511.

Bonnomet A, Syne L, Brysse A, Feyereisen E, Thompson EW, Noel A, Foidart JM, Birembaut P, Polette M, Gilles C. 2012. A dynamic in vivo model of epithelial-to-mesenchymal transitions in circulating tumor cells and metastases of breast cancer. Oncogene 31: 3741-3753.

Bornholdt J, Friis S, Godiksen S, Poulsen SS, Santoni-Rugiu E, Bisgaard HC, Lothe IM, Ikdahl T, Tveit KM, Johnson E, et al. 2011. The level of claudin-7 is reduced as an early event in colorectal carcinogenesis. BMC Cancer 11: 65.

Bronsert P, Enderle-Ammour K, Bader M, Timme S, Kuehs M, Csanadi A, Kayser G, Kohler I, Bausch D, Hoeppner J, et al. 2014. Cancer cell invasion and EMT marker expression: A three-dimensional study of the human cancer-host interface. J Pathol 234: 410-422.

Cavallaro U, Christofori G. 2004. Cell adhesion and signalling by cadherins and Ig-CAMs in cancer. Nat Rev Cancer 4: 118-132.

Celia-Terrassa T, Meca-Cortes O, Mateo F, Martinez de Paz A, Rubio N, Arnal-Estape A, Ell BJ, Bermudo R, Diaz A, Guerra-Rebollo M, et al. 2012. Epithelial-mesenchymal transition can suppress major attributes of human epithelial tumor-initiating cells. J Clin Invest 122: 1849-1868.

Chang CC, Hsu WH, Wang CC, Chou CH, Kuo MY, Lin BR, Chen ST, Tai SK, Kuo ML, Yang MH. 2013. Connective tissue growth factor activates pluripotency genes and mesenchymal-epithelial transition in head and neck cancer cells. Cancer Res 73: 4147-4157.

Cheung KJ, Padmanaban V, Silvestri V, Schipper K, Cohen JD, Fairchild AN, Gorin MA, Verdone JE, Pienta KJ, Bader JS, et al. 2016. Polyclonal breast cancer metastases arise from collective dissemination of keratin 14-expressing tumor cell clusters. Proc Natl Acad Sci 113: E854-E863.

Clark AG, Vignjevic DM. 2015. Modes of cancer cell invasion and the role of the microenvironment. Curr Opin Cell Biol 36: 13-22.

Comijn J, Berx G, Vermassen P, Verschueren K, van Grunsven L, Bruyneel E, Mareel M, Huylebroeck D, van Roy F. 2001. The two-handed E box binding zinc finger protein SIP1 downregulates E-cadherin and induces invasion. Mol Cell 7: 1267-1278.

De Arcangelis A, Hamade H, Alpy F, Normand S, Bruyere E, Lefebvre O, Mechine-Neuville A, Siebert S, Pfister V, Lepage $\mathrm{P}$, et al. 2016. Hemidesmosome integrity protects the colon against colitis and colorectal cancer. Gut. doi: 10.1136/ gutjnl-2015-310847.

De Craene B, Berx G. 2013. Regulatory networks defining EMT during cancer initiation and progression. Nat Rev Cancer 13: 97-110.

Eger A, Aigner K, Sonderegger S, Dampier B, Oehler S, Schreiber M, Berx G, Cano A, Beug H, Foisner R. 2005. DeltaEF1 is a transcriptional repressor of E-cadherin and regulates epithelial plasticity in breast cancer cells. Oncogene 24: $2375-2385$. 
Fan F, Samuel S, Evans KW, Lu J, Xia L, Zhou Y, Sceusi E, Tozzi F, Ye XC, Mani SA, et al. 2012. Overexpression of snail induces epithelial-mesenchymal transition and a cancer stem cell-like phenotype in human colorectal cancer cells. Cancer Med 1: 5-16.

Fidler IJ. 2003. The pathogenesis of cancer metastasis: The 'seed and soil' hypothesis revisited. Nat Rev Cancer 3: $453-458$.

Fischer KR, Durrans A, Lee S, Sheng J, Li F, Wong ST, Choi H, El Rayes T, Ryu S, Troeger J, et al. 2015. Epithelial-tomesenchymal transition is not required for lung metastasis but contributes to chemoresistance. Nature 527: 472-476.

Friedl P, Gilmour D. 2009. Collective cell migration in morphogenesis, regeneration and cancer. Nat Rev Mol Cell Biol 10: $445-457$.

Friedl P, Locker J, Sahai E, Segall JE. 2012. Classifying collective cancer cell invasion. Nat Cell Biol 14: 777-783.

Frixen UH, Behrens J, Sachs M, Eberle G, Voss B, Warda A, Lochner D, Birchmeier W. 1991. E-cadherin-mediated cellcell adhesion prevents invasiveness of human carcinoma cells. J Cell Biol 113: 173-185.

Greenburg G, Hay ED. 1982. Epithelia suspended in collagen gels can lose polarity and express characteristics of migrating mesenchymal cells. J Cell Biol 95: 333-339.

Grigore AD, Jolly MK, Jia D, Farach-Carson MC, Levine H. 2016. Tumor budding: The name is EMT. Partial EMT. J Clin Med 5: 51.

Grosse-Wilde A, Fouquier d'Herouel A, McIntosh E, Ertaylan G, Skupin A, Kuestner RE, del Sol A, Walters KA, Huang S. 2015. Stemness of the hybrid epithelial/mesenchymal state in breast cancer and its association with poor survival. PLoS One 10: $\mathrm{e} 0126522$.

Guo W, Keckesova Z, Donaher JL, Shibue T, Tischler V, Reinhardt F, Itzkovitz S, Noske A, Zurrer-Hardi U, Bell G, et al. 2012. Slug and Sox 9 cooperatively determine the mammary stem cell state. Cell 148: 1015-1028.

Gupta PB, Onder TT, Jiang G, Tao K, Kuperwasser C, Weinberg RA, Lander ES. 2009. Identification of selective inhibitors of cancer stem cells by high-throughput screening. Cell 138: 645-659.

Hajra KM, Chen DY, Fearon ER. 2002. The SLUG zinc-finger protein represses E-cadherin in breast cancer. Cancer Res 62: $1613-1618$.

Hong T, Watanabe K, Ta CH, Villarreal-Ponce A, Nie Q, Dai X. 2015. An Ovol2-Zeb1 mutual inhibitory circuit governs bidirectional and multi-step transition between epithelial and mesenchymal states. PLoS Comput Biol 11: e1004569.

Ikenouchi J, Matsuda M, Furuse M, Tsukita S. 2003. Regulation of tight junctions during the epithelium-mesenchyme transition: Direct repression of the gene expression of claudins/ occludin by Snail. J Cell Sci 116: 1959-1967.

Jeanes A, Gottardi CJ, Yap AS. 2008. Cadherins and cancer: How does cadherin dysfunction promote tumor progression? Oncogene 27: 6920-6929.

Jolly MK, Boareto M, Huang B, Jia D, Lu M, Ben-Jacob E, Onuchic JN, Levine H. 2015a. Implications of the hybrid epithelial/mesenchymal phenotype in metastasis. Front Oncol 5: 155.

Jolly MK, Jia D, Boareto M, Mani SA, Pienta KJ, Ben-Jacob E, Levine H. 2015b. Coupling the modules of EMT and stemness: A tunable 'stemness window' model. Oncotarget 6: $25161-25174$.

Jorda M, Olmeda D, Vinyals A, Valero E, Cubillo E, Llorens A, Cano A, Fabra A. 2005. Upregulation of MMP-9 in MDCK epithelial cell line in response to expression of the Snail transcription factor. J Cell Sci 118: 3371-3385.

Jordan NV, Johnson GL, Abell AN. 2011. Tracking the intermediate stages of epithelial-mesenchymal transition in epithelial stem cells and cancer. Cell Cycle 10: 28652873.

Kalluri R, Weinberg RA. 2009. The basics of epithelial-mesenchymal transition. J Clin Invest 119: 1420-1428.
Kelley LC, Lohmer LL, Hagedorn EJ, Sherwood DR. 2014. Traversing the basement membrane in vivo: A diversity of strategies. J Cell Biol 204: 291-302.

Kessenbrock K, Plaks V, Werb Z. 2010. Matrix metalloproteinases: Regulators of the tumor microenvironment. Cell 141: $52-67$.

Khalil AA, Friedl P. 2010. Determinants of leader cells in collective cell migration. Integr Biol (Camb) 2: 568-574.

Kong D, Banerjee S, Ahmad A, Li Y, Wang Z, Sethi S, Sarkar FH. 2010. Epithelial to mesenchymal transition is mechanistically linked with stem cell signatures in prostate cancer cells. PLoS One 5: e12445.

Labelle M, Begum S, Hynes RO. 2011. Direct signaling between platelets and cancer cells induces an epithelial-mesenchymal-like transition and promotes metastasis. Cancer Cell 20: $576-590$.

Lee M, Vasioukhin V. 2008. Cell polarity and cancer-cell and tissue polarity as a non-canonical tumor suppressor. J Cell Sci 121: $1141-1150$.

Li W, Kang Y. 2016. Probing the fifty shades of EMT in metastasis. Trends Cancer 2: 65-67.

Li HJ, Reinhardt F, Herschman HR, Weinberg RA. 2012. Cancer-stimulated mesenchymal stem cells create a carcinoma stem cell niche via prostaglandin E2 signaling. Cancer Discov 2: $840-855$

Li J, Liu J, Li P, Mao X, Li W, Yang J, Liu P. 2014. Loss of LKB1 disrupts breast epithelial cell polarity and promotes breast cancer metastasis and invasion. $J$ Exp Clin Cancer Res 33: 70.

Long H, Xiang T, Qi W, Huang J, Chen J, He L, Liang Z, Guo B, Li Y, Xie R, et al. 2015. CD133+ ${ }^{+}$ovarian cancer stem-like cells promote non-stem cancer cell metastasis via CCL5 induced epithelial-mesenchymal transition. Oncotarget 6: 5846-5859.

Lundgren K, Nordenskjold B, Landberg G. 2009. Hypoxia, Snail and incomplete epithelial-mesenchymal transition in breast cancer. Br J Cancer 101: 1769-1781.

Mani SA, Guo W, Liao MJ, Eaton EN, Ayyanan A, Zhou AY, Brooks M, Reinhard F, Zhang CC, Shipitsin M, et al. 2008. The epithelial-mesenchymal transition generates cells with properties of stem cells. Cell 133: 704-715.

Martin TA, Jiang WG. 2009. Loss of tight junction barrier function and its role in cancer metastasis. Biochim Biophys Acta 1788: $872-891$.

Martin TA, Mansel RE, Jiang WG. 2010. Loss of occludin leads to the progression of human breast cancer. Int J Mol Med 26: $723-734$.

Martin-Belmonte F, Gassama A, Datta A, Yu W, Rescher U, Gerke V, Mostov K. 2007. PTEN-mediated apical segregation of phosphoinositides controls epithelial morphogenesis through Cdc42. Cell 128: 383-397.

Martinez-Estrada OM, Culleres A, Soriano FX, Peinado H, Bolos V, Martinez FO, Reina M, Cano A, Fabre M, Vilaro S. 2006. The transcription factors Slug and Snail act as repressors of Claudin-1 expression in epithelial cells. Biochem $J$ 394: 449-457.

McCaffrey LM, Montalbano J, Mihai C, Macara IG. 2012. Loss of the Par3 polarity protein promotes breast tumorigenesis and metastasis. Cancer Cell 22: 601-614.

Miyoshi A, Kitajima Y, Kido S, Shimonishi T, Matsuyama S, Kitahara K, Miyazaki K. 2005. Snail accelerates cancer invasion by upregulating MMP expression and is associated with poor prognosis of hepatocellular carcinoma. Br J Cancer 92: $252-258$.

Morel AP, Lievre M, Thomas C, Hinkal G, Ansieau S, Puisieux A. 2008. Generation of breast cancer stem cells through epithelial-mesenchymal transition. PLoS One 3: e2888.

Munster PN, Troso-Sandoval T, Rosen N, Rifkind R, Marks PA, Richon VM. 2001. The histone deacetylase inhibitor suberoylanilide hydroxamic acid induces differentiation of human breast cancer cells. Cancer Res 61: 8492-8497.

Nassour M, Idoux-Gillet Y, Selmi A, Come C, Faraldo ML, Deugnier MA, Savagner P. 2012. Slug controls stem/progen- 
itor cell growth dynamics during mammary gland morphogenesis. PLoS One 7: e53498.

Nieto MA, Huang RY, Jackson RA, Thiery JP. 2016. EMT: 2016. Cell 166: $21-45$.

Ocana OH, Corcoles R, Fabra A, Moreno-Bueno G, Acloque H, Vega S, Barrallo-Gimeno A, Cano A, Nieto MA. 2012. Metastatic colonization requires the repression of the epithelialmesenchymal transition inducer Prrx1. Cancer Cell 22: $709-$ 724.

Ohkubo T, Ozawa M. 2004. The transcription factor Snail downregulates the tight junction components independently of E-cadherin downregulation. J Cell Sci 117: 16751685.

Okada H, Danoff TM, Kalluri R, Neilson EG. 1997. Early role of Fsp1 in epithelial-mesenchymal transformation. Am J Physiol 273: F563-F574.

Pattabiraman DR, Bierie B, Kober KI, Thiru P, Krall JA, Zill C, Reinhardt F, Tam WL, Weinberg RA. 2016. Activation of PKA leads to mesenchymal-to-epithelial transition and loss of tumor-initiating ability. Science 351: aad3680.

Paulsson M. 1992. Basement membrane proteins: Structure, assembly, and cellular interactions. Crit Rev Biochem Mol Biol 27: 93-127.

Rasheed ZA, Yang J, Wang Q, Kowalski J, Freed I, Murter C, Hong SM, Koorstra JB, Rajeshkumar NV, He X, et al. 2010. Prognostic significance of tumorigenic cells with mesenchymal features in pancreatic adenocarcinoma. $J$ Natl Cancer Inst 102: $340-351$.

Revenu C, Gilmour D. 2009. EMT 2.0: Shaping epithelia through collective migration. Curr Opin Genetics Dev 19: 338-342.

Sampson VB, David JM, Puig I, Patil PU, de Herreros AG, Thomas GV, Rajasekaran AK. 2014. Wilms' tumor protein induces an epithelial-mesenchymal hybrid differentiation state in clear cell renal cell carcinoma. PLoS One 9: e102041.

Scheel C, Eaton EN, Li SH, Chaffer CL, Reinhardt F, Kah KJ, Bell G, Guo W, Rubin J, Richardson AL, et al. 2011. Paracrine and autocrine signals induce and maintain mesenchymal and stem cell states in the breast. Cell 145: 926-940.

Schliekelman MJ, Taguchi A, Zhu J, Dai X, Rodriguez J, Celiktas M, Zhang Q, Chin A, Wong CH, Wang H, et al. 2015. Molecular portraits of epithelial, mesenchymal, and hybrid states in lung adenocarcinoma and their relevance to survival. Cancer Res 75: 1789-1800.

Spaderna S, Schmalhofer O, Wahlbuhl M, Dimmler A, Bauer K, Sultan A, Hlubek F, Jung A, Strand D, Eger A, et al. 2008. The transcriptional repressor ZEB1 promotes metastasis and loss of cell polarity in cancer. Cancer Res 68: 537-544.

Takai E, Tan X, Tamori Y, Hirota M, Egami H, Ogawa M. 2005. Correlation of translocation of tight junction protein Zonula occludens-1 and activation of epidermal growth factor receptor in the regulation of invasion of pancreatic cancer cells. Int J Oncol 27: 645-651.

Taki M, Verschueren K, Yokoyama K, Nagayama M, Kamata N. 2006. Involvement of Ets-1 transcription factor in inducing matrix metalloproteinase- 2 expression by epithelial-mesenchymal transition in human squamous carcinoma cells. Int $J$ Oncol 28: 487-496.

Tan TZ, Miow QH, Miki Y, Noda T, Mori S, Huang RY, Thiery JP. 2014. Epithelial-mesenchymal transition spectrum quantification and its efficacy in deciphering survival and drug responses of cancer patients. EMBO Mol Med 6: 1279-1293.
Trimboli AJ, Fukino K, de Bruin A, Wei G, Shen L, Tanner SM, Creasap N, Rosol TJ, Robinson ML, Eng C, et al. 2008. Direct evidence for epithelial-mesenchymal transitions in breast cancer. Cancer Res 68: 937-945.

Tsai JH, Yang J. 2013. Epithelial-mesenchymal plasticity in carcinoma metastasis. Genes Dev 27: 2192-2206.

Tsai JH, Donaher JL, Murphy DA, Chau S, Yang J. 2012. Spatiotemporal regulation of epithelial-mesenchymal transition is essential for squamous cell carcinoma metastasis. Cancer Cell 22: $725-736$.

Uchida H, Maruyama T, Ono M, Ohta K, Kajitani T, Masuda H, Nagashima T, Arase T, Asada H, Yoshimura Y. 2007. Histone deacetylase inhibitors stimulate cell migration in human endometrial adenocarcinoma cells through up-regulation of glycodelin. Endocrinology 148: 896-902.

Vleminckx K, Vakaet L Jr, Mareel M, Fiers W, van Roy F. 1991. Genetic manipulation of E-cadherin expression by epithelial tumor cells reveals an invasion suppressor role. Cell 66: $107-$ 119 .

Warrell RP Jr, de The H, Wang ZY, Degos L. 1993. Acute promyelocytic leukemia. N Engl J Med 329: 177-189.

Westcott JM, Prechtl AM, Maine EA, Dang TT, Esparza MA, Sun H, Zhou Y, Xie Y, Pearson GW. 2015. An epigenetically distinct breast cancer cell subpopulation promotes collective invasion. J Clin Invest 125: 1927-1943.

Whiteman EL, Liu CJ, Fearon ER, Margolis B. 2008. The transcription factor snail represses Crumbs 3 expression and disrupts apico-basal polarity complexes. Oncogene 27: 3875 3879.

Xie G, Ji A, Yuan Q, Jin Z, Yuan Y, Ren C, Guo Z, Yao Q, Yang $\mathrm{K}$, Lin X, et al. 2014. Tumour-initiating capacity is independent of epithelial-mesenchymal transition status in breast cancer cell lines. Br J Cancer 110: 2514-2523.

$\mathrm{Xu}$ WS, Parmigiani RB, Marks PA. 2007. Histone deacetylase inhibitors: Molecular mechanisms of action. Oncogene 26: 5541-5552.

Yamamoto M, Taguchi Y, Ito-Kureha T, Semba K, Yamaguchi N, Inoue J. 2013. NF-кB non-cell-autonomously regulates cancer stem cell populations in the basal-like breast cancer subtype. Nat Commun 4: 2299.

Yang J, Mani SA, Donaher JL, Ramaswamy S, Itzykson RA, Come C, Savagner P, Gitelman I, Richardson A, Weinberg RA. 2004. Twist, a master regulator of morphogenesis, plays an essential role in tumor metastasis. Cell 117: 927-939.

Ye X, Tam WL, Shibue T, Kaygusuz Y, Reinhardt F, Ng Eaton E, Weinberg RA. 2015. Distinct EMT programs control normal mammary stem cells and tumour-initiating cells. Nature 525: $256-260$.

Yu M, Bardia A, Wittner BS, Stott SL, Smas ME, Ting DT, Isakoff SJ, Ciciliano JC, Wells MN, Shah AM, et al. 2013. Circulating breast tumor cells exhibit dynamic changes in epithelial and mesenchymal composition. Science 339: $580-584$.

Zheng X, Carstens JL, Kim J, Scheible M, Kaye J, Sugimoto H, Wu CC, LeBleu VS, Kalluri R. 2015. Epithelial-to-mesenchymal transition is dispensable for metastasis but induces chemoresistance in pancreatic cancer. Nature 527: 525-530.

Zhou D, Kannappan V, Chen X, Li J, Leng X, Zhang J, Xuan S. 2016. RBP2 induces stem-like cancer cells by promoting EMT and is a prognostic marker for renal cell carcinoma. Exp Mol Med 48: e238. 


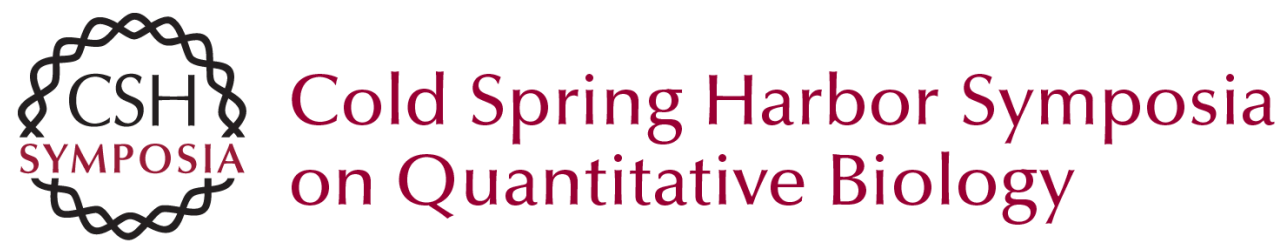

\section{Targeting the Epithelial-to-Mesenchymal Transition: The Case for Differentiation-Based Therapy}

Diwakar R. Pattabiraman and Robert A. Weinberg

Cold Spring Harb Symp Quant Biol 2016 81: 11-19 originally published online January 5, 2017 Access the most recent version at doi:10.1101/sqb.2016.81.030957

References This article cites 90 articles, 21 of which can be accessed free at: http://symposium.cshlp.org/content/81/11.full.html\#ref-list-1

Creative This article is distributed under the terms of the

Commons http://creativecommons.org/licenses/by-nc/4.0/, which permits reuse and License redistribution, except for commercial purposes, provided that the original author and source are credited.

Email Alerting Receive free email alerts when new articles cite this article - sign up in Service the box at the top right corner of the article or click here. 